\title{
A utilização da terapia do humor no ambiente hospitalar: revisão integrativa
}

\author{
Andressa Lopes de Souza* Mayra Oliveria Camargo Rodrigues** \\ Flavia Pereira Carnaúba*** Luciene Rodrigues Barbosa****
}

Resumo: Objetivo - analisar as produções científicas disponíveis sobre a atuação dos Doutores da Alegria e uso do humor no ambiente hospitalar. Método - trata-se de um estudo bibliográfico, descritivo usando como método de pesquisa a revisão integrativa da literatura. Os dados foram coletados utilizando a base de dados Literatura Latino-Americana e do Caribe em Ciências da Saúde (LILACS), com associação dos descritores enfermagem pediátrica, criança hospitalizada, jogos e brinquedos. Resultados - os estudos abordaram a importância do humor oferecido pelos Doutores da Alegria, a influencia positiva desta estratégia para as crianças e sua família em um ambiente hospitalar. A maior incidência de publicações ocorreu nos anos de 2005 e 2009. Quanto à autoria, evidenciou-se maior número de publicações realizadas pelos enfermeiros sobre os demais profissionais. Conclusão acredita-se que na prática da humanização no atendimento às crianças hospitalizadas a enfermagem pode proporcionar um ambiente terapêutico alegre, e por meio do uso de atividades lúdicas, que propicie o bem estar da criança e de seus familiares.

Descritores: Enfermagem pediátrica; Jogos e brinquedos; Criança hospitalizada.

The use of humor therapy in hospital environment: integrative review

Abstract: Objective - To analyze the scientific production available about the performance of Clowndoctors and use of humor in a hospital setting. Method - This is a bibliographical study, using the descriptive method of integrative literature review. Data were collected using the database Latin American and Caribbean Health Sciences (LILACS) with association of descriptors pediatric nursing, hospitalized children, games and toys. Results - The studies addressed the importance of mood offered by Doctors of Joy, the positive influence of this strategy for children and their families in a hospital setting. The highest incidence of publications occurred in 2005 and 2009. As to authorship, showed a higher number of publications made by nurses on the other professionals. Conclusion - it is believed that the practice of humane care for hospitalized children in nursing can provide a therapeutic environment cheerful, and through the use of play activities that would encourage the well-being of children and their families.

Descriptors: Pediatric nursing; games and toys; Child hospitalized.

\footnotetext{
*Graduanda em Enfermagem na Anhanguera Educacional - Faculdades Integradas Torricelli (UNI-ANHANGUERA), Guarulhos, SP, Brasil

**Especialista em Gerontologia pela Anhanguera Educacional - Faculdades Integradas Torricelli (UNIANHANGUERA), Guarulhos, SP, Brasil

${ }^{* * *}$ Mestranda em Enfermagem na Universidade de Guarulhos (UNG), Guarulhos, SP, Brasil.

${ }^{* * * *}$ Mestre em Enfermagem pela Universidade de São Paulo (USP), São Paulo, SP, Brasil.
} 


\section{Introdução}

O ambiente hospitalar é cercado de regras regulamentadoras que, inúmeras vezes, ameaçam o comportamento espontâneo da criança. A instituição hospitalar visa cuidar do aspecto físico, esquecendo-se inúmeras vezes de ver a criança em sua totalidade - o seu aspecto biopsicossociais. A hospitalização traz inúmeros transtornos à vida da criança e ocasiona uma série de alterações em sua rotina e na de sua família. Logo, que é hospitalizada a criança é afastada de sua rotina diária, do ambiente familiar e em alguns casos do brincar, e submetida a experiências dolorosas e restrições físicas.

0 desenvolvimento de atividades lúdicas no ambiente hospitalar tem minizado estas experiências traumáticas, por meio do lúdico podemos nos comunicar com as crianças, mostrando-Ihes de forma mais compreensível e prepará-las para enfrentar novas situações ${ }^{1}$.

Por meio do brincar a criança pode conhecer detalhes da vida no hospital de tal forma que vivencie a função real e não fantasiada do instrumental hospitalar e dos métodos empregados no decorrer da assistência ${ }^{2-3}$. Durante a brincadeira a enfermeira pode analisar se as informações foram ou não suficientes, uma vez que, nem todas as crianças exprimem espontaneamente o que estão pensando ou sentindo, e muito menos, respondem de maneira a corresponder àquilo que se espera das perguntas diretas.

Quanto às crianças hospitalizadas o brincar tem um importante valor terapêutico, auxiliando na recuperação, interferindo no comportamento, desenvolvimento, restabelecimento físico e emocional ${ }^{4-5}$. A dramatização torna o processo de hospitalização menos traumático e mais alegre, oferecendo melhores condições, e contribuindo com a humanização da assistência junto à equipe de enfermagem ${ }^{6}$.

Na visão da criança, ele auxilia no desenvolvimento físico, psicológico, social e moral; permite-lhe observar o que ocorre consigo, libera temores, raiva, frustração e ansiedade. Ajuda a criança, ainda, a tornar evidentes seus pensamentos e sentimentos, proporcionando satisfação, diversão e espontaneidade.

A expectativa do uso de brinquedo na Enfermagem Pediátrica é a de servir como meio de comunicação entre os profissionais e a criança, detectando a singularidade e a necessidade de cada uma, construindo uma imagem hospitalar acolhedora ${ }^{3,7}$. Considerando que 0 ambiente hospitalar transmite ao paciente a sensação de temor frente ao tratamento ${ }^{7}, 0$ Ministério da Saúde criou no Brasil um o Programa Nacional de Humanização da Assistência Hospitalar (PNHAH), que se transformou na Política Nacional de Humanização da Atenção e Gestão do SUS (HumanizaSUS) que busca "promover atividades de valorização e de cuidados aos trabalhadores da saúde, contemplando ações voltadas para a promoção da saúde e qualidade de vida no trabalho"8. Esta política apóia iniciativas que visem desenvolver atividade humanizadora dentro das instituições de saúde.

Decorrente deste movimento de humanização do cuidado surgiu em alguns hospitais os Doutores da Alegria, que são palhaços que realizam visitas às crianças internadas levando as crianças e familiares inúmeros benéficos através do sorriso $0^{9-10}$. Os Doutores da Alegria é um projeto sem fins lucrativos criada em 1991 foi à primeira instituição criada no país que objetiva levar ao ambiente hospitalar o humor, carinho, e a arte do palhaço para crianças e adultos ${ }^{11}$.

Saúde (Santa Maria), v.39, n.2, p.49-56, 2013. A utilização da terapia do humor no ambiente hospitalar: Revisão Integrativa ISSN 2236-5834 Reduzindo desta maneira o estresse e contribuindo para que a hospitalização interfira 0 mínimo possivel na vida diária da criança hospitalizada.

Diante do exposto, este estudo tem como objetivo analisar as produções científicas disponíveis sobre a atuação dos Doutores da Alegria e uso do humor no ambiente hospitalar. 


\section{Método}

Trata-se de um estudo bibliográfico, descritivo usando como o método de pesquisa a revisão integrativa. A revisão integrativa é um método que proporciona uma síntese de conhecimento sobre determinada temática, fundamenta a prática ao conhecimento cientifico e permite a incorporação de questões relevantes da pesquisa ${ }^{12}$.

Para a elaboração da revisão integrativa foram percorridas as seguintes etapas: definição da questão norteadora (problema) e objetivo da pesquisa; o estabelecimento de critérios de inclusão e exclusão das publicações (seleção da amostra); busca na literatura; análise e categorização dos estudos, apresentação e discussão dos resultados ${ }^{13}$. Para nortear pesquisa, formularam-se a seguinte pergunta: 0 que a literatura tem publicado sobre a atuação dos Doutores da Alegria e uso do humor no ambiente hospitalar?

Definiu-se como fonte de busca a Literatura Latino Americana e do Caribe em Ciencias da Saúde (LILACS), que é uma considerada referência na produção na área da saúde nos países da America Latina e Caribe. Foram utilizados os seguintes descritores: enfermagem pediátrica, criança hospitalizada, jogos e brinquedos.

Para a seleção dos estudos desta revisão integrativa os seguintes critérios de elegibilidade: artigos completos publicados em português, inglês e espanhol; que possuíam aderência ao objetivo proposto e que abordem a temática estudada. A busca pelas produções foi conduzida no período entre março e julho de 2012.

Elaborou-se para análise e posterior síntese dos artigos um instrumento para a coleta das informações, a fim de responder a questão norteadora, que contemplou os seguintes aspectos considerados: nome do artigo, objetivos, resultados e recomendações/conclusões. Os resultados foram dispostos em duas tabelas para melhor visualização das analises.

\section{Resultados e Discussão}

Foram identificados 15 estudos, do quais após análise se observou que 09 artigos abordavam o tema proposto e atendiam aos critérios estabelecidos. Estes foram selecionadas para compor a amostra desta revisão integrativa.

Tendo como objetivo manter uma avaliação a cega, os artigos foram codificados (A01, A02,..., A09), e somente após a análise do conteúdo receberam a identificação dos autores. 


\begin{tabular}{|c|c|c|c|}
\hline CODIGO & AUTORES & Periódicos & Ano de publicação \\
\hline $\mathrm{A} 01$ & Gomes R, Mitre RMA. & Ciência \& Saúde coletiva & 2004 \\
\hline $\mathrm{A} 02$ & Masetti, M. & $\begin{array}{c}\text { Interface - Comunicação, Saúde, } \\
\text { Educação }\end{array}$ & 2005 \\
\hline $\mathrm{A} 03$ & $\begin{array}{c}\text { Richman LS, Kubzansky L, } \\
\text { Maselke J, Kawachi I, Choo P, } \\
\text { Bauer M. }\end{array}$ & Health Psychology & 2005 \\
\hline A04 & $\begin{array}{c}\text { Ferreira CCM, Remedi PP, Lima } \\
\text { RAG. }\end{array}$ & Rev. Bras. Enferm; & 2006 \\
\hline A05 & Cordazzo STD, Vieira MLA & Estudos e Pesquisas em Psicologia & 2007 \\
\hline A06 & $\begin{array}{c}\text { Lima RAG, Azevedo E.F, } \\
\text { Nascimento LC, Rocha SMM. }\end{array}$ & Esc. Anna Nery - Rev Enferm. USP & 2008 \\
\hline $\mathrm{A} 07$ & Oliveira RR., Oliveira ICS & Rev. Esc. Enferm. USP & 2009 \\
\hline A08 & Araujo TCCF, Guimarães TB & Estudo Pesquisa Psicologia & 2009 \\
\hline A09 & Weber FS & J. Pediatr. & 2010 \\
\hline
\end{tabular}

Observa-se maior incidência de publicações (três artigos) durante os anos de $2005 \mathrm{e}$ 2009. Quanto aos periódicos, constata-se que a maioria é da área de enfermagem e psicologia. Nota-se que a enfermagem se apresenta muito sensibilizada e disposta em investigar acerca dos Doutores da Alegria e o uso do humor no ambiente hospitalar. Este fato pode estar relacionado o cuidado direto que 0 enfermeiro proporciona a criança e a família durante a hospitalização ${ }^{14}$.

Os artigos analisados buscaram investigar aspectos de mudança comportamental da criança, a vivência da equipe de enfermagem com Doutores da Alegria, as brincadeiras realizadas com as crianças, ente outros, que podem ser visualizados no Quadro 02.

Quadro 2 - Apresentação da síntese de artigos incluídos na revisão, 2012.

\begin{tabular}{|c|c|c|}
\hline CÓDIGO & TÍTULO & OBJETIVO \\
\hline $\mathrm{A} 01$ & $\begin{array}{l}\text { A promoção do brincar no contexto da } \\
\text { hospitalização infantil como ação em } \\
\text { saúde }\end{array}$ & $\begin{array}{l}\text { Conhecer a percepções o paciente } \\
\text { pediátrico e de seu acompanhante sobre } \\
\text { as suas interações com palhaço-doutor. }\end{array}$ \\
\hline A02 & Doutores da ética da alegria & $\begin{array}{c}\text { Descrever o papel dos Doutores da } \\
\text { Alegria e sua atuação no ambiente } \\
\text { hospitalar. }\end{array}$ \\
\hline A03 & $\begin{array}{l}\text { Positive emotion and health: going } \\
\text { beyond the negative. }\end{array}$ & $\begin{array}{l}\text { Avaliar as relações entre emoções } \\
\text { positivas e de saúde. }\end{array}$ \\
\hline A04 & $\begin{array}{l}\text { A música como recurso no cuidado à } \\
\text { criança hospitalizada: uma intervenção } \\
\text { possível? }\end{array}$ & $\begin{array}{l}\text { Analisar a produção bibliográfica da } \\
\text { enfermagem pediátrica quanto à utilização } \\
\text { da música como recurso terapêutico no } \\
\text { espaço hospitalar, a fim de identificar o } \\
\text { estado do conhecimento desta área nesse } \\
\text { campo. }\end{array}$ \\
\hline
\end{tabular}

Saúde (Santa Maria), v.39, n.2, p.49-56, 2013. Autilização da terapia do humor no ambiente hospitalar: Revisão Integrativa 52 ISSN 2236-5834 


\begin{tabular}{|c|c|c|}
\hline A05 & $\begin{array}{l}\text { A brincadeira e suas implicações nos } \\
\text { processos de aprendizagem e de } \\
\text { desenvolvimento. }\end{array}$ & $\begin{array}{c}\text { Discutir as contribuições que a } \\
\text { brincadeira pode oferecer à aprendizagem } \\
\text { e ao desenvolvimento infantil. }\end{array}$ \\
\hline A06 & $\begin{array}{l}\text { The art of Clown theater in care for } \\
\text { hospitalized children }\end{array}$ & $\begin{array}{l}\text { Foi explorar a experiência da utilização } \\
\text { da arte do teatro clown no cuidado as } \\
\text { crianças hospitalizadas, a partir de uma } \\
\text { atividade desenvolvida por alunos de } \\
\text { cursos de graduação da área da saúde }\end{array}$ \\
\hline A07 & $\begin{array}{l}\text { Os Doutores da Alegria na Unidade de } \\
\text { Internação Pediátrica: experiência da } \\
\text { equipe de enfermagem }\end{array}$ & $\begin{array}{l}\text { Descrever os conhecimentos da equipe } \\
\text { de enfermagem quanto à atuação dos } \\
\text { Doutores da Alegria e analisar as } \\
\text { experiências da equipe de enfermagem } \\
\text { quanto à atuação dos Doutores da Alegria. }\end{array}$ \\
\hline A08 & $\begin{array}{l}\text { Interações entre voluntários e usuários } \\
\text { em onco - hematologia pediátrica: um } \\
\text { estudo sobre os palhaços-doutores" }\end{array}$ & $\begin{array}{l}\text { (1) Conhecer as percepções do paciente } \\
\text { pediátrico e de seu acompanhante sobre } \\
\text { suas interações com o palhaço-doutor; } \\
\text { (2) Conhecer as percepções do } \\
\text { voluntário sobre suas interações com } \\
\text { usuários (pacientes e acompanhantes) e } \\
\text { profissionais de saúde, assim como sobre } \\
\text { sua própria atuação como palhaço-doutor; } \\
\text { (3) Descrever e compreender as } \\
\text { interações estabelecidas entre voluntários } \\
\text { e usuários. }\end{array}$ \\
\hline A09 & $\begin{array}{l}\text { The influence of playful activities on } \\
\text { children's anxiety during the preoperative } \\
\text { period at the outpatient surgical center. }\end{array}$ & $\begin{array}{l}\text { Verificar a influência das atividades } \\
\text { lúdicas realizadas durante o pré-operatório } \\
\text { sobre a ansiedade de crianças } \\
\text { participantes do projeto de recreação } \\
\text { terapêutica desenvolvido no CCA do } \\
\text { HCPA }\end{array}$ \\
\hline
\end{tabular}

A partir dos objetivos propostos nos estudos, é possível identificar que as produções cientificas buscam compreender a percepção do paciente e seu acompanhante sobre a atuação dos Doutores da Alegria no processo de restabelecimento da saúde.

$\mathrm{O}$ estudo A01 e A07 abordam as diversas formas do brincar, o significado da atividade para os profissionais e o desenvolvimento infantil a partir do brincar ${ }^{15-16}$. As atividades lúdicas que envolvem teatro com utilização dos palhaços buscam demonstrar as realidades cômicas das fraquezas de cada um, que no cotidiano passam despercebidos, transformando situações desagradáveis de maneira hilária para criança.

Os estudos A02, A06 e A08 ressaltam que as ações desenvolvidas por meio de palhaços como os Doutores da Alegria, são voltadas para o ambiente hospitalar onde são desenvolvidas atividades como: oficinas boas misturas para profissionais de saúde, rodas

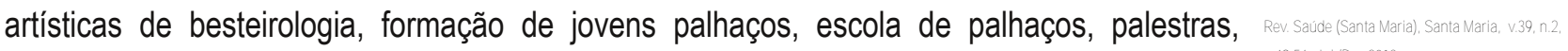
palhaços em rede e diversos outros projetos ${ }^{17-18}$.

Expressando a arte como forma de comunicação a importância do brincar fica evidente, uma vez, que o brincar é fundamental para o desenvolvimento, socialização, interação e ISSN 2236.5843 valores morais da criança ${ }^{19}$. 
O estudo A04 revela a importância da música no processo de recuperação e também evidenciou que por meio da música alguns pacientes conseguem expressar os sentimentos de tristeza, ansiedade decorrente de um sofrimento ocasionado por algum tipo de abuso ou negligencia ${ }^{20}$. Ainda 0 estudo $\mathrm{A} 03$ afirma que 0 uso de atividades lúdicas durante a internação hospitalar leva os pacientes a apresentarem-se um pouco mais relaxados durante os procedimentos invasivos, diminuindo assim significativamente 0 nível de ansiedade durante o período de internação ${ }^{21}$.

O estudo A07 e A09 aponta que a presença constante de um familiar durante a hospitalização associada à oferta de um ambiente aconchegante, onde a criança sente-se motivada e estimulada a brincar de forma mais intensa, facilita 0 trabalho da equipe de enfermagem ${ }^{9,13}$. Durante a hospitalização, o brinquedo tem importante valor terapêutico, e 0 ato de brincar, torna o contexto menos traumático e insere alegria na rotina promovendo a busca pela recuperação da saúde.

Alguns profissionais de enfermagem relatam que durante o processo de hospitalização, é visível tanto na equipe, quanto nas crianças já visitadas pelos Doutores da Alegria expressar verbalmente a vontade em revê-lo sentem-se descontraídas com a equipe, pacientes e familiares ficando nítida a avaliação evolutiva do paciente no decorrer dos dias ${ }^{9}$.

Acredita-se que a abordagem destes possa possibilitar melhor compreensão sobre os Doutores da Alegria e dos benefícios proporcionados uso do humor de modo terapêutico no ambiente hospitalar.

\section{Considerações Finais}

Inserir a arte, a música, a promoção do brincar, a humanização, as técnicas do teatro clown e dos Doutores da Alegria, são formas de relacionamento interpessoal como instrumento do cuidar, levando o humor, a otimização, a valorização da alegria na vida do profissional, da criança e de seus familiares.

Através deste tipo de comunicação, a criança tende a apresentar menor rejeição alimentar, colaborar com a realização de exames, administração de medicamento, melhora progressiva em seu quadro, além de colaborar com os profissionais.

Levar o lúdico ao contexto hospitalar é o ponto primordial como forma de auxiliar a criança a reduzir suas ansiedades e conflitos internos e a partir daí, atenuar suas angustias a cerca do que sente falta em sua rotina diária, como seus brinquedos, sua casa, escola, amigos e familiares.

Frente ao exposto, considera-se relevante a investigação sobre as atividades lúdicas realizadas pelos Doutores da Alegria, sugere-se o desenvolvimento de estudos exploratórios sobre a temática que possibilitem maior compreensão sobre esta prática e apontem estratégias para que a equipe de enfermagem possa desenvolver estas atividades no ambiente hospitalar.

Saúde (Santa Maria), v.39, n.2, p.49-56, 2013. A utilização da terapia do humor no ambiente hospitalar: Revisão Integrativa ISSN 2236-5834

\section{Referências Bibliográficas}

1. Maia EBS, Ribeiro CA, Borba RIH. Brinquedo terapêutico: benefícios vivenciados por enfermeiras na prática assistencial à criança e família. Rev Gaúcha Enferm. 2008; 29(1):39-46. 
2. Ribeiro CA, Borba RIH. A criança e o brinquedo no hospital. In: Almeida FA, Sabatés AL, organizadores. Enfermagem pediátrica: a criança, o adolescente e sua família no hospital. São Paulo: Manole; 2008. p. 6577.

3. Barbosa LR. O papel da brinquedoteca no contexto da hospitalização infantil como ação de enfermagem em Parintins-AM: relato de experiência. In: Anais do II Simpósio O Brinquedo e a Assistência de Enfermagem à Criança e sua Família e o III Workshop Brincando com a criança: estratégia integradora da assistência de enfermagem; 2012 set. 20-22; São Paulo. São Paulo: UNIFESP/GEbrinq-Grupo de Estudos do Brinquedo Terapêutico; 2012.

4. Francischinelli AGB, Almeida FA, Fernandes DMSO. Routine use of therapeutic play in the care of hospitalized children: nurses' perceptions. Acta Paul Enferm [Internet]. 2012 [acesso em 2012 fev 21];25(1):18-23. Disponível em: <http://www.scielo.br/pdf/ape/v25n1/en_v25n1a04.pdf>

5. Maia EBS, Ribeiro CA, Borba RIH. Compreendendo a sensibilização do enfermeiro para o uso do brinquedo terapêutico na prática assistencial à criança. Rev Esc Enferm USP [Internet]. 2011 [acesso em 2012 fev 21];45(4):839-46. Disponível em: <http://www.scielo.br/pdf/reeusp/v45n4/v45n4a07.pdf>

6. Souza LPS, Silva CC, Brito JCA, Santos APO, Fonseca ADG, Lopes JR, et al. The Therapeutic Toy and playful in the vision of nursing team. J Health Sci Inst [Internet]. 2012 [acesso em 2012 fev 21];30(4):354-8. Disponivel em: <http://www.unip.br/comunicacao/publicacoes/ics/edicoes/2012/04_outdezN30_n4_2012_p354a358.pdf>

7. Padoin SMM, Paula CC, Tronco CS, Ribeiro AC, Santos Eps, Hoffmann IC, et al. Crianças que tem HIVIAIDS e seus familiares/cuidadores: experiência de acompanhamento multidisciplinar. Rev Saúde (Santa Maria) [ Internet]. 2009 [acesso em 2012 mar 2];35(2):51-6. Disponível em: $<$ <ttp://cascavel.ufsm.br/revistas/ojs-2.2.2/index.php/revistasaude/article/view/4184/2526>

8. Brasil. Ministério da Saúde. Secretaria de Atenção à Saúde. Núcleo Técnico da Política Nacional de Humanização. Acolhimento nas práticas de produção de saúde. $2^{\mathrm{a}}$ ed. Brasilia: Editora do Ministério da Saúde; 2010. (Série B. Textos Básicos de Saúde).

9. Oliveira RR, Oliveira IC. Os doutores da alegria na unidade de internação pediátrica: experiências da equipe de enfermagem. Esc Anna Nery Rev Enferm. 2008;12(2):230-6.

10. Doutores da Alegria. Palhaços em hospitais [Internet]. 2003 [acesso em 2012 maio 10]. Disponível em: $<$ www.doutoresdaalegria.org.br/download/Pesqlnt_port.pdf>.

11. Doutores da Alegria. Palhaços em hospitais [Internet]. 2003 [acesso em 2012 maio 10]. Disponível em: $<w w w$. doutoresdaalegria.org.br/download/Pesqlnt_port.pdf>.

12. Souza MT, SilvA MD, Carvalho R. Revisão Integrativa: o que é e como fazer. Rev Einstein [Internet]. 2010 jun [acesso em 2012 set 12];8(1):102-06. Disponível em:<http://apps.einstein.br/revista/arquivos/PDF/1134Einsteinv8n1_p102-106_port.pdf>.

13. Mendes KDS, Silveira RCCP, Galvão CM. Revisão integrativa: método de pesquisa para a incorporação de evidências na saúde e na enfermagem. Texto \& Contexto Enferm. 2008;17(4):758-64.

14. Weber FS. The influence of playful activities on children's anxiety during the preoperative period at the outpatient surgical center. J Pediatr (Rio J) [Internet]. 2010 [acesso em 2012 abr 18];86(3):209-14. Disponível em: <http://www.scielo.br/pdf/jped/v86n3/en_a08v86n3.pdf>.

15. Gomes R, Mitre RMA. A promoção do brincar no contexto da hospitalização infantil como ação de saúde. Ciênc Saúde Coletiva. 2004;9(1):147-54.

16. Cordazzo STD, Vieira ML. A brincadeira e suas implicações nos processos de aprendizagem e de desenvolvimento. Estud Pesqui Psicol [Internet]. 2007 [acesso em 2012 mar 2];7(1):122-36. Disponível em: $<$ <ttp://www.revispsi.uerj.br/v7n1/artigos/pdf/v7n1a09.pdf>

17. Masetti M. Doutores da ética da alegria. Interface Comun Saúde Educ. 2005;(9)17:453-8.

Rev. Saúde (Santa Maria), Santa Maria, v.39, n.2, p.49-56, Jul./Dez.2013 Souza, A. L.; et al.

18. Araujo TCCF, Guimarães TB. Interações entre voluntários e usuários em onco-hematologia pediátrica: um estudo sobre os "palhaços-doutores". Estud pesqui psicol [Internet]. 2009 [acesso em 2012 mar 2];9(3):63247. Disponivel em: <http://pepsic.bvsalud.org/pdf/epp/v9n3/v9n3a06.pdf> 
19. Lima, RAG, Azevedo EF, Nascimento LC, Rocha SMM. The art of Clown theater in care for hospitalized children. Rev Esc Enferm USP [Internet]. 2009 [acesso em 2012 maio 10];43(1):178-85. Disponível em: $<$ http://www.scielo.br/pdf/reeusp/v43n1/en_24.pdf>

20. Ferreira CCM, Remedi PP, Lima RAG. A música como recurso no cuidado à criança hospitalizada: uma intervenção possível? Rev Bras Enferm [Internet]. 2006 [acesso em 2012 maio 10];59(5):689-93. Disponível em: <http://www.scielo.br/pdf/reben//59n5/v59n5a18.pdf>

21. Richman LS, Kubzansky L, Maselko J, Kawachi I, Choo P, Bauer M. Positive emotion and health: going beyond the negative. Health Psychology. 2005;24(4):422-9.

\section{Andressa Lopes de Souza}

Endereço para correspondência - Rua Narciso Zanardi, 32. Vila Zanardi, Cep: 07020121, Guarulhos, SP, Brasil.

Currículo Lattes: http://lattes.cnpq.br/6564345816885386

E-mail: enf.sorocaba@gmail.com

Recebido em 21 de fevereiro de 2013.

Aprovado em 15 de outubro de 2013. 